\title{
GENTRIFICAÇÃO: A TRIBUTAÇÃO COMO ATENUANTE DA SEGREGAÇÃO SOCIAL E URBANA
}

\section{GENTRIFICATION: TAXATION AS MITIGATING THE SOCIAL AND URBAN SEGREGATION}

\author{
${ }^{1}$ Roney Carlos de Carvalho
}

\section{RESUMO}

O objetivo deste artigo é examinar como a tributação pode ser utilizada para reduzir os efeitos da segregação urbana e social causados pela gentrificação, atentando para os aspectos que devem ser levados em consideração nesse empreendimento, à luz do sistema tributário brasileiro. Dessa forma, torna-se necessário refletir sobre o tema e como a tributação pode apresentar soluções para a desigualdade promovida por este fenômeno.

Palavras-Chave: Gentrificação; Tributação; Operações Urbanas Consorciadas; Desigualdade

\begin{abstract}
The purpose of this article is to examine how taxation can be used to reduce the effects of urban and social segregation caused by gentrification, paying attention to the aspects that must be taken into account in this project, in the light of the Brazilian tax system. Thus, it is necessary to reflect on the subject and how taxation can provide solutions to the inequality promoted by this phenomenon.
\end{abstract}

Keywords: Gentrification; Taxation; Urban Operations Consortium; Inequality

\footnotetext{
${ }^{1}$ Mestrando em Direito e Ordem Jurídica Constitucional pela Universidade Federal do Ceará - UFC, Ceará (Brasil). E-mail: rc.carvalho21@gmail.com
} 


\title{
1 INTRODUÇÃO
}

A aquisição de bens imóveis com finalidade de vendê-los ou alugá-los posteriormente, na expectativa que seus valores aumentem durante lapso de tempo decorrido, a chamada especulação imobiliária, é fato que traz prejuízos imensuráveis para a estabilidade da sociedade na medida em que reflete as grandes disparidades entre os que vivem com os rendimentos do capital acumulado e os que sobrevivem somente com a retribuição por sua força de trabalho.

O processo de enobrecimento de localidades historicamente ocupadas por camadas mais populares da sociedade e que aos poucos se veem forçadas a migrarem para outras redondezas, Gentrification ou Gentrificação (aportuguesamento do termo), decorrência em parte da especulação imobiliária, é realidade que deveria repercutir no perfil das políticas públicas.

Álvaro Luís dos Santos Pereira apresenta as teorias que tentam explicar a gênese da gentrificação:

\begin{abstract}
Esse debate polarizou-se em torno de duas correntes explicativas não necessariamente inconciliáveis, mas que atribuíram ênfase a fatores distintos na tentativa de identificar as forças motrizes desse processo. De um lado, as teorias centradas na demanda formularam modelos explicativos que gravitavam em torno de fatores como mudanças culturais e escolhas de consumidores, caracterizando a gentrificação como efeito de uma guinada nos estilos de vida e nas preferências de indivíduos de maior poder aquisitivo, que teriam passado a manifestar um interesse crescente pelos centros urbanos. De outro lado, as teorias centradas na oferta interpretaram a generalização dos processos de gentrificação como parte integrante de um movimento mais amplo de reestruturação do capitalismo, enfatizando os nexos existentes entre esse fenômeno, a ascensão de políticas urbanas de inspiração neoliberal e o processo de

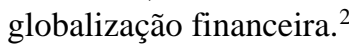

Se, partindo-se da premissa que, o direito existe em função da sua capacidade de promover a paz social, não podemos nos abster de sobre o tema gentrificação traçarmos algumas considerações que possam contribuir para o seu correto entendimento e apreciação, bem como municiar o direito contra as investidas do capital privado de maneira a elaborar meios para garantir a realização da justiça social.

\footnotetext{
${ }^{2}$ PEREIRA, Alvaro Luiz dos Santos. Intervenções em centros urbanos e conflitos distributivos: modelos regulatórios, circuitos de valorização e estratégias discursivas. 308f. 2015. Tese (Doutorado em Direito). Universidade de São Paulo - São Paulo, 2015. p. 19.
} 
O objetivo deste artigo é examinar como a tributação pode ser utilizada para reduzir os efeitos da segregação urbana e social causados pela gentrificação, atentando para os aspectos que devem ser levados em consideração nesse empreendimento, à luz do sistema tributário brasileiro.

\section{GENTRIFICAÇÃO E SEUS PROBLEMAS}

O primeiro ponto que precisa ser definido, em um texto dedicado a tributação como instrumento de redução dos efeitos da gentrificação, é o que se entende por gentrificação.

O termo Gentrificação, que se refere ao aportuguesamento da palavra Gentrification que por sua vez representa um neologismo da palavra gentry (pequena nobreza), representa um fenômeno observado primeiramente pela socióloga inglesa Ruth Glass em London: Aspects of change.

Glass observou que após investimentos num bairro de Londres, que apesar de bem localizado era reduto da população mais carente da cidade e, portanto, desvalorizado, a população pobre que o habitava inicia um gradativo deslocamento para regiões mais periféricas simultaneamente a chegada de novos habitantes, mais abastados, na mesma região. Em razão de seus status, e da riqueza que tinham, a autora denominou-o de Gentrificação, conforme dito linhas acima.

Apesar do pioneirismo de Glass, os estudos mais aprofundados sobre gentrificação correspondem às pesquisas do Neil Smith, que reconhece em Glass um marco histórico, apresentando o texto no qual o fenômeno foi pela primeira vez abordado:

\footnotetext{
Um após o outro, numerosos bairros operários londrinos foram invadidos pelas classes médias alta e baixa. Locais com casinhas modestas, com dois aposentos no térreo e dois em cima, foram retomadas quando os contratos de aluguel expiraram, e se tornaram elegantes residências de alto preço. Residências vitorianas maiores que tinham mudado de função - ou seja, haviam passado a ser utilizadas como pensões familiares ou sub-locadas - recuperaram um bom nível de status. Esse processo de gentrificação, uma vez começado em um bairro, se estendeu rapidamente até que quase todas as camadas populares que aí moravam originalmente tivessem deixado o lugar e que todas as características sociais tivessem mudado. ${ }^{3}$
}

\footnotetext{
${ }^{3}$ GLASS apud SMITH, Neil. A gentrificação generalizada: de uma anomalia local à "regeneração" urbana como estratégia urbana global. In: BIDOU-ZACHARIASEN, Catherine (Org). De volta à cidade. São Paulo: ANNABLUME, 2006. pp. 60
} 
Uma tradução literal de gentrification poderia ser enobrecimento ou elitização de uma área. Corresponde ao aporte de investimentos de ordem pública ou privada em uma determinada área degradada e historicamente habitada pelas camadas mais populares da sociedade que sempre passaram à margem das políticas públicas e que, agora, passa por uma completa reestruturação proporcionando uma revolução na realidade daquele espaço: segurança pública fortalecida, reformas das ruas e aperfeiçoamento da iluminação pública, aformoseamento de parques e passeios públicos, inserção de novas linhas de transporte público, incremento das opções de lazer (restaurantes, bares, cinemas, teatros etc.). alterações que trariam inúmeros benefícios para aquela população, exceto pelo fato de que lá mais não podem permanecer.

Todos esses aperfeiçoamentos produzem um incremento no custo de vida daquela região que é praticamente impossível para as pessoas, que sobrevivem simplesmente com o produto da sua força de trabalho, manterem-se na região gentrificada.

Andrei Mikhail Zaiatz Crestani, reúne os elementos para compreensão do processo de gentrificação:

\begin{abstract}
A gentrificação pressupõe transformações de centros urbanos em suas dimensões materiais, econômicas, sociais e simbólicas, bem como uma reconfiguração da economia local no contexto no qual se manifesta, designando um processo de deslocamento de um grupo social participante das classes populares do centro e o enobrecimento dessas áreas antes degradadas. ${ }^{4}$
\end{abstract}

A gentrificação decorre, portanto, sempre uma alterações materiais, econômicos e sociais em uma determinada região com a posterior fuga da população que historicamente a habitava.

Segundo Smith, a construção de espaços gentrificados passa por três ondas: "a primeira poderia ser chamada de gentrificação esporádica; a segunda seria a consolidação do processo; enquanto que na terceira estamos frente a uma gentrificação generalizada"5.

\footnotetext{
${ }^{4}$ CRESTANI, Andrei Mikhail Zaiatz. As faces (in) visíveis da regeneração urbana: rua Riachuelo e a produção de um cenário gentrificado. Cadernos Metrópole., v. 17, n. 33, 2015. p. 180.

${ }^{5}$ SMITH, Neil. A gentrificação generalizada: de uma anomalia local à "regeneração" urbana como estratégia urbana global. In: BIDOU-ZACHARIASEN, Catherine (Org). De volta à cidade. São Paulo: ANNABLUME, 2006. p. 63.
} 
A onda de gentrificação identificada como esporádica é levada a cabo por representantes da "classe média que arriscam ao investir em um local desvalorizado pelo mercado imobiliário, por causa do diferencial favorável do custo do aluguel e das benfeitorias, ou infra-estruturas ali existentes"6.

A segunda onda de gentrificação, a fase de consolidação, caracteriza-se pela participação do mercado imobiliário com apoio de incentivos públicos, leia-se, desde financiamentos por bancos públicos até renúncia de receitas fiscais passando pela concessão das mais variadas benesses que os ricos e afortunados sempre gozaram perante os governantes.

Os agentes gentrificadores dessa nova onda não assumem tantos riscos e movem-se sobretudo, pelos altos índices de rendimento do capital investido que essas áreas, que acumulam um grande déficit de investimentos ao longo do tempo, podem proporcionar. Em ambientes nos quais nunca se procedeu a qualquer aporte de investimentos de qualquer ordem, sejam públicos ou privados, o mínimo investido redunda em máximo de lucros. Perfeito para a lógica capitalista: minimizar custos, maximizar ganhos. Conforme já observou Lodi, comentando sobre desigualdade na obra de Thomas Piketty:

\footnotetext{
Essa dinâmica tende a ser exarcebada no século XXI quando se espera, como demonstra o autor, que as taxas de crescimento econômico gravitem em torno de $1 \mathrm{a}$ $1,5 \%$, enquanto a remuneração do capital em média deverá ficar situada na faixa anaal de 4 a 5\%. De acordo com o estudo, o crescimento futuro dos países já desenvolvido não deve superar esse patamar, ao contrário do que ocorreu na fase áurea do século XX, dos anos 1950 a 1970, em função dos investimentos na reconstrução e na recuperação da economia após as duas Guerras Mundiais. Presentemente, crescimento mais elevado só será encontrado nos países emergentes, que ainda guardam um déficit a ser superado em relação aos países mais desenvolvidos. ${ }^{7}$
}

Importando este raciocínio para o aspecto dos processos de gentrificação fica claro porque ambientes que historicamente foram abandonados de investimentos guardam um nicho de mercado muito valioso, sobretudo pelo potencial que apresentam de produzirem lucros astronômicos em relação aos valores de capital que necessita para alavancar tal negócio. Este

\footnotetext{
6 ZOLINI, Gustavo Pimenta de Pádua. A Inflexão do Conceito Gentrificação em Conjuntos Urbanos Patrimoniais Em Cidades De Pequeno Porte: Os Casos Mineiros De São Thomé Das Letras E Tiradentes. 181f. 2007. Dissertação (Mestrado em Arquitetura). Universidade Federal de Minas Gerais - Belo Horizonte, 2007. p. 41.

${ }^{7}$ RIBEIRO, Ricardo Lodi. O capital no século XXI e a justiça fiscal: uma contribuição de Thomas Piketty para uma reforma tributária no Brasil. Revista de Direito Público de Economia - RDPE. Ano 13, n. 50, p. 197-28. abr./jun. 2015. p. 199.
} 
ponto ficará mais claro quando analisarmos a teoria da renda diferencial proposta por Niel Smith para explicar os processos de gentrificação.

Nessa fase, ou onda, os maiores ganhos correspondem preponderantemente aos provenientes da especulação imobiliária, patrocinada, vergonhosamente, por financiamentos públicos.

A terceira onda, a gentrificação generalizada, caracteriza-se pela ampliação das características do ambiente gentrificado para o seu entorno. Sobre essa terceira onda, Zolini asserta:

\footnotetext{
O tecido urbano passa a ser afetado, e ruas comerciais inteiras, parques, restaurantes, mercados, museus, cinemas e todo tipo de imóvel de uso não residencial será valorizado pelas arcas internacionais, corporações ou investidores com os quais a nova classe média se identifica, mudando assim a paisagem urbana e amalgamando uma paisagem cultural onde o gentrificador possa se identificar ${ }^{8}$.
}

Concluída a gentrificação no bairro originário, seus efeitos começar a irradiar para os bairros circunvizinhos a demonstrar claramente que aquele ambiente fora projetado para representar classes bem definidas: a média e alta. Enquanto as camadas mais populares são forçadas a migrarem para regiões afastadas daquele próspero bairro que não mais o pertence a sua realidade.

Neil Smith considera, para explicar o processo de gentrificação, a teoria do rent gap ou teoria da renda diferencial ${ }^{9}$, expressando a diferença entre a renda capitalizada e a renda potencial em propriedades imobiliárias. Em regiões que durante muito tempo ficaram esquecidas de qualquer tipo de investimento, a propriedades imóveis lá existentes sofreram uma desvalorização expressiva, diminuíram o seu valor de mercado, noutras palavras a renda capitalizada diminuiu. Simultaneamente, a renda potencial destas propriedades subiu exponencialmente, proporcionando possibilidades de ganhos igualmente expressivos, chamando a atenção de investidores e de capital especulativo.

\footnotetext{
${ }^{8}$ ZOLINI, Gustavo Pimenta de Pádua. A Inflexão do Conceito Gentrificação em Conjuntos Urbanos Patrimoniais Em Cidades De Pequeno Porte: Os Casos Mineiros De São Thomé Das Letras E Tiradentes. 181f. 2007. Dissertação (Mestrado em Arquitetura). Universidade Federal de Minas Gerais - Belo Horizonte, 2007. p. 43.

${ }^{9}$ SMITH, Neil. A gentrificação generalizada: de uma anomalia local à "regeneração" urbana como estratégia urbana global. In: BIDOU-ZACHARIASEN, Catherine (Org). De volta à cidade. São Paulo: ANNABLUME, 2006. p. 66.
} 
$\mathrm{Na}$ lógica capitalista, um ambiente passível de gentrificação, isto é, um local onde as perspectivas de valorização são altas, representa forte atrativo para investimentos que proporcionarão ganhos astronômicos e com reduzido risco, em virtude de financiamentos de ordem pública.

Se certo ou errado, justo ou injusto, o fato é que nossa Constituição congrega o princípio da livre iniciativa e se em algum momento um empresário, ou grupos de empresários vislumbram em determinado espaço a oportunidade de maximizarem seus lucros é evidente que, considerando a atual ordem econômico-jurídico-social, não nos resta muitas opções.

De outro giro, quando é o Estado mesmo que promove, mediante uma série de incentivos das mais variadas ordens - de isenções fiscais ao regulamento das operações urbanas consorciadas -, os processos de segregação social e urbana de determinada população é razoável esperar uma postura ativa estatal, quer seja implantando políticas de saneamento e desenvolvimento aos bairros que passam a receber a população segregada quer seja, e aqui de fundamental importância, cobrando as respectivas contribuições de melhoria sobre as propriedades que tiveram valorização imobiliária em decorrência da atuação estatal que enobreceu aquela área bem como instituindo a progressividade do imposto sobre a propriedade territorial urbana.

\section{OPERAÇÕES URBANAS CONSORCIADAS}

Em 10 de julho de 2001 é publica da a lei 10.257, o Estatuto da Cidade, que trouxe em seu bojo mecanismos que possibilitariam as municipalidades reduzirem a pressão fiscal que se verificava, após o advento da nova ordem jurídico constitucional, ante o aumento substancial das demandas sociais que pelo Município deveriam ser atendidas e a reduzida arrecadação tributária.

Fundado na pretensa superioridade que o setor privado teria em comparação com (in)eficiência estatal para a realização de seus objetivos, típico do pensamento neoliberal de estado absenteísta, o Estatuto da Cidade inaugurou na ordem jurídica a possibilidade da participação do capital privado nas políticas de urbanização das cidades, nomeadamente, as 
Parcerias Público-Privadas (PPP's) e as Operações Urbanas Consorciadas. A ordem era: atrair investimento privado para as cidades.

Alvaro Luis dos Santos Pereira apregoa que:

Iniciou-se um movimento articulado em que um conjunto crescente de atividades antes desempenhadas diretamente por entes públicos passaram a ser delegadas à iniciativa privada, ao mesmo tempo em que a agenda de governos locais passou a ser progressivamente orientada para o estabelecimento de um ambiente favorável à ampliação da esfera de atuação de agentes privados ${ }^{10}$.

Servem de exemplo do mencionado acima as Operações Urbanas Consorciadas previstas no Estatuto das Cidades como instrumento da política urbana:

Art. 32. Lei municipal específica, baseada no plano diretor, poderá delimitar área para aplicação de operações consorciadas.

$\S 1^{\circ}$ Considera-se operação urbana consorciada o conjunto de intervenções e medidas coordenadas pelo Poder Público municipal, com a participação dos proprietários, moradores, usuários permanentes e investidores privados, com o objetivo de alcançar em uma área transformações urbanísticas estruturais, melhorias sociais e a valorização ambiental.

$\S 2^{\circ}$ Poderão ser previstas nas operações urbanas consorciadas, entre outras medidas:

I - a modificação de índices e características de parcelamento, uso e ocupação do solo e subsolo, bem como alterações das normas edilícias, considerado o impacto ambiental delas decorrente;

II - a regularização de construções, reformas ou ampliações executadas em desacordo com a legislação vigente.

III - a concessão de incentivos a operações urbanas que utilizam tecnologias visando a redução de impactos ambientais, e que comprovem a utilização, nas construções e uso de edificações urbanas, de tecnologias que reduzam os impactos ambientais e economizem recursos naturais, especificadas as modalidades de design e de obras a serem contempladas. (Incluído pela Lei no 12.836, de 2013)

Art. 33. Da lei específica que aprovar a operação urbana consorciada constará o plano de operação urbana consorciada, contendo, no mínimo:

I - definição da área a ser atingida;

II - programa básico de ocupação da área;

III - programa de atendimento econômico e social para a população diretamente afetada pela operação;

IV - finalidades da operação;

V - estudo prévio de impacto de vizinhança;

VI - contrapartida a ser exigida dos proprietários, usuários permanentes e investidores privados em função da utilização dos benefícios previstos nos incisos I e II do § 2o do art. 32 desta Lei;

VI - contrapartida a ser exigida dos proprietários, usuários permanentes e investidores privados em função da utilização dos benefícios previstos nos incisos I, II e III do § 20 do art. 32 desta Lei; (Redação dada pela Lei nº 12.836, de 2013)

${ }^{10}$ PEREIRA, Alvaro Luiz dos Santos. Intervenções em centros urbanos e conflitos distributivos: modelos regulatórios, circuitos de valorização e estratégias discursivas. 308f. 2015. Tese (Doutorado em Direito).

Universidade de São Paulo - São Paulo, 2015. p. 127. 
VII - forma de controle da operação, obrigatoriamente compartilhado com representação da sociedade civil.

VIII - natureza dos incentivos a serem concedidos aos proprietários, usuários permanentes e investidores privados, uma vez atendido o disposto no inciso III do $§ 20$ do art. 32 desta Lei. (Incluído pela Lei no 12.836, de 2013)

$\S 1$ o Os recursos obtidos pelo Poder Público municipal na forma do inciso VI deste artigo serão aplicados exclusivamente na própria operação urbana consorciada.

§ 2 o A partir da aprovação da lei específica de que trata o caput, são nulas as licenças e autorizações a cargo do Poder Público municipal expedidas em desacordo com o plano de operação urbana consorciada.

Art. 34. A lei específica que aprovar a operação urbana consorciada poderá prever a emissão pelo Município de quantidade determinada de certificados de potencial adicional de construção, que serão alienados em leilão ou utilizados diretamente no pagamento das obras necessárias à própria operação.

$\S 1^{\circ}$ Os certificados de potencial adicional de construção serão livremente negociados, mas conversíveis em direito de construir unicamente na área objeto da operação.

$\S 2^{\circ}$ Apresentado pedido de licença para construir, o certificado de potencial adicional será utilizado no pagamento da área de construção que supere os padrões estabelecidos pela legislação de uso e ocupação do solo, até o limite fixado pela lei específica que aprovar a operação urbana consorciada.

Art. 34-A. Nas regiões metropolitanas ou nas aglomerações urbanas instituídas por lei complementar estadual, poderão ser realizadas operações urbanas consorciadas interfederativas, aprovadas por leis estaduais específicas. (Incluído pela Lei ${ }^{\circ} 13.089$, de 2015)

Parágrafo único. As disposições dos arts. 32 a 34 desta Lei aplicam-se às operações urbanas consorciadas interfederativas previstas no caput deste artigo, no que couber. (Incluído pela Lei no 13.089, de 2015).

As operações urbanas consistem na cobrança pela outorga de potencial construtivo adicional, e representa forma de captação de recursos para custear o desenvolvimento urbano usando somente capital privado. $\mathrm{O}$ que, em tese, diminuiria o aperto fiscal das municipalidades que já sofrem com a baixa arrecadação tributária e ainda, conforme visto, teve sua carga de responsabilidades aumentadas pela Constituição Federal.

O potencial construtivo adicional é negociado livremente mediante a venda de Certificado de Potencial Adicional Construtivo (CEPAC), art. 34 do Estatuto das Cidades, o que concede direitos urbanísticos na zona de abrangência da operação urbana, conforme estabelecido em lei. Alvaro Luis comenta em sua brilhante tese de doutoramento os aspectos dos CEPAC's:

Dentre os argumentos apresentados para se defender as potencialidades oferecidas pelas operações urbanas, costuma-se dizer que elas seriam um dos instrumentos jurídicos que permitiriam ao poder público dividir os ônus de ações de qualificação urbanística com seus beneficiários diretos (SANDRONI, 2001; ALFONSIN, 2004, 2008). Contribuiriam, assim, para se colocar em prática uma das bandeiras defendidas pelo movimento da reforma urbana, a chamada captura das "mais valias urbanas". Esse princípio é apontado por juristas e urbanistas como um dos desdobramentos da 
afirmação da função social da propriedade na Constituição Federal. A ideia subjacente a ele é a de que normalmente o poder público é quem arca com os custos do processo de urbanização, enquanto proprietários privados se beneficiam de seus resultados por meio da valorização imobiliária sem que tenham contribuído para seu custeio ${ }^{11}$.

Na realidade, a utilização das operações urbanas consorciadas representa o aval do estado para o fortalecimento da especulação imobiliária. O investidor privado comprará Certificado de Potencial Adicional Construtivo, na expectativa de que os melhoramentos efetivados conduza a valorização imobiliária. Neste sentido Alvaro Luis dos Santos Pereira aponta:

Do ponto de vista do governo, ambos os mecanismos consistem em formas de capitalização de expectativas de arrecadação para a alavancagem de projetos urbanos. Do ponto de vista do investidor, ambos figuram como apostas na valorização imobiliária $^{12}$.

Longe de contribuir para o desenvolvimento da cidade como um todo, as operações urbanas consorciadas conduzem ao aumento da desigualdades espaciais existentes ao concentrar os investimentos em zonas limitadas, nas quais, já havia interesse de investidores em virtude, sobretudo, da certa valorização imobiliária decorrentes de mínimo dispêndio financeiro. Segue-se a máxima capitalista: maximizar ganhos, reduzir gastos com o plus do baixo risco oportunizado em tais operações urbanas.

Entre tomar medidas eficazes na realização de uma justiça social, os governantes preferem não incomodar o grande capital, continuam atuando ou omitindo-se de forma a perpetuar a desigualdade, contribuindo para a formação de novos burgos, os espaços gentrificados, onde se encontram na atualidade os detentores do capital.

\section{TRIBUTAÇÃO COMO FATOR DE CORREÇÃO DA SEGREGAÇÃO SOCIAL E URBANA}

A história da tributação está intimamente relacionada com a do próprio Estado. Constitui-se dos mecanismos postos a disposição do Estado para a arrecadação dos recursos

\footnotetext{
${ }^{11}$ PEREIRA, Alvaro Luiz dos Santos. Intervenções em centros urbanos e conflitos distributivos: modelos regulatórios, circuitos de valorização e estratégias discursivas. 308f. 2015. Tese (Doutorado em Direito). Universidade de São Paulo - São Paulo, 2015. p. 141.

12 PEREIRA, Alvaro Luiz dos Santos. Intervenções em centros urbanos e conflitos distributivos: modelos regulatórios, circuitos de valorização e estratégias discursivas. 308f. 2015. Tese (Doutorado em Direito). Universidade de São Paulo - São Paulo, 2015. p. 141.
} 
que se fazem necessários para fazer frente às despesas decorrentes da própria estruturação do Estado.

A tributação é instituto tão antigo quanto a noção de sociedade. Mas que, por óbvio sofreu alterações e aprimoramentos conforme o desenvolvimento da própria sociedade e do Estado. Se nascida meramente como expressão de poder, como intromissão do soberano sobre a propriedade privada, a tributação aos poucos foi tomando forma de relação jurídica (vínculo entre duas ou mais pessoas, ao qual as normas jurídicas atribuem efeitos obrigatórios). Até o advento da Constituição da República Federativa de 1988, o Direito Tributário era fundado no poder de tributar do Estado, desde que observados os direitos e garantias individuais. Esse poder era irrestrito, sobretudo no que tange à destinação do produto da arrecadação. Ou seja, o Estado tinha o poder de tributar, mas não havia qualquer dever de destinar a sua arrecadação. Com o advento da $\mathrm{CF} / 88$, o Estado deixou de ter o poder de tributar para exercer a função de tributar. Neste momento, a exigência do tributo passou a ter como finalidade a busca de recursos em prol da sociedade, em busca de um crescimento socioeconômico.

Como pontua Ricardo Lodi, forte nas lições Liam Murphy (O Mito da Propriedade) e Piketty (A economia da desigualdade) a tributação exerce papel importante na redução das desigualdades:

O combate às desigualdades sociais pela via da tributação se dá não só pela redistribuição de renda, através da introdução de prestações positivas aos mais pobres, a partir de recursos orçamentários obtidos por meio da tributação dos mais ricos, mas ainda pela distribuição de rendas, que não tem propriamente o conteúdo distributivo, mas baseia-se apenas nas receitas e na ideia de divisão justa do ônus fiscal pela capacidade contributiva, por meio da progressividade e da tributação sobre as grandes riquezas, a fim de evitar a concentração de renda. ${ }^{13}$

Entregar a execução da política urbana ao setor privado - através de qualquer dos mecanismos colocados a disposição, parceria público-privada, operações urbanas consorciadas, concessões onerosas, etc -, não nos parece que possa conduzir a redução das desigualdades. Contrariamente, a utilização destes mecanismos é fator fundamental para a produção de localidades gentrificadas, com altos indíces de desenvolvimento em comparação com as regiões que não foram concebidas para receberem tais instrumentos de política urbana.

\footnotetext{
${ }^{13}$ RIBEIRO, Ricardo Lodi. Piketty e a Reforma Tributária igualitária no Brasil. Revista de Finanças Públicas, Tributação e Desenvolvimento - RFPTD, v.3, n.3. Rio de Janeiro: UERJ, 2015. Disponível em: www.epublicacoes.uerj.br/index.php/rfptd/article/view/15587, p.7.
} 
E o motivo parece óbvio: as municipalidades ao emitirem os Certificados de Potencial Adicional Construtivo estaria garatindo um investimento que certamente produzirá resultados, confome anota Alvaro Pereira:

\begin{abstract}
O uso desse instrumento urbanístico imprime à produção do espaço uma lógica bastante semelhante à de uma empresa que se capitaliza por meio da realização de ofertas de ações no mercado de capitais. Se a remuneração de acionistas que compram ações de uma empresa é condicionada por sua performance econômica, o retorno proporcionado a um investidor que compra CEPACs depende da dinâmica do mercado imobiliário na área da operação urbana. Para que haja interesse por estes certificados, é preciso que se ofereçam condições para que ocorra um processo de valorização imobiliária. A aplicação dos recursos auferidos com sua venda na execução do programa de intervenções é o fator objetivo capaz de fazer com que esse processo aconteça ${ }^{14}$.
\end{abstract}

O capitalismo é naturalmente divergente, tende inercialmente, para acumulação de capital nas mãos de quem já o detém ao passo que o indivíduo de depende somente de sua força de trabalho tende a manter nesta posição, perpetuando as desigualdades. Por isso são necessárias medidas estatais no sentido de opor-se ao processo de acumulação de capital e redução das desigualdades. Essas medidas corporificam-se na tributação.

No que toca aos processos de gentrificação, uma posição estatal tendente a redução de seus efeitos danosos já está delineada, mas absurdamente deixada à margem de aplicação. Trata-se da contribuição de melhoria.

A contribuição de melhoria é tributo vinculado cujo fato gerador consiste na valorização imobiliária decorrente de obra pública e que, nas liçoes do mestre Hugo de Brito Machado é tributo que tem por finalidade "a realização da justiça, impedindo que o proprietário de imóvel valorizado com uma obra pública tenha proveito maior do que para as pessoas em geral resultam das obras públicas" $" 15$.

Assim a contribuição de melhoria é perfeitamente aplicável à espécie, ao combate dos efeitos danosos da gentrificação. Ademais é expressamente reconhecida como instrumento de política urbana. Mas, qual o motivo de sua inaplicação? Estamos com Machado quando afirma:

\footnotetext{
${ }^{14}$ PEREIRA, Alvaro Luiz dos Santos. Intervenções em centros urbanos e conflitos distributivos: modelos regulatórios, circuitos de valorização e estratégias discursivas. 308f. 2015. Tese (Doutorado em Direito). Universidade de São Paulo - São Paulo, 2015. p. 140.

${ }^{15}$ MACHADO, Hugo de Brito. Contribuição de Melhoria. Revista Fórum de Direito Tributário - RFDT. Belo Horizonte, ano 9, n. 50, p. 7-25, mar./abr. 2011. p. 7.
} 
Preferimos acreditar que a verdadeira razão para a não cobrança da contribuição de melhoria, no Brasil, é a exigência legal de publicação do orçamento da obra e do direito do contribuinte de impugnar o respectivo valor, porque as obras pública em nosso país, desgraçadamente, são quase todas objeto de vergonhoso superfaturamento. ${ }^{16}$

Acrescente-se ao lado da corrupção, apontada por Hugo de Brito Machado, o reconhecimento da influência que os detentores do capital imobiliário têm sobre as tomadas de decisões referentes as medidas a serem aplicadas na execução do planejamento urbano. O lobby não pode ser desconsiderado e a pressão que o lobby capitalista tende a ser mais persuasivo que a preocupação com os anseios da classes mais populares.

\section{CONCLUSÕES}

Do que foi examinado ao longo deste texto, conclui-se que a gentrificação constituise em processo típico de especulação imobiliária, que necessita de muito investimento privado e respaldo do poder público para o atendimento de demandas de interesse eminentemente particulares.

Em função da prevalência do interesse privado sobre o interesse público na decisão de qual o melhor instrumento para a execução do planejamento urbano, consideramos que a Gentrificação apresenta efeitos nocivos, sobretudo por perpetuar uma lógica capitalista de lucros acima de quaisquer objetivos altuístas e de busca do bem comum. Promove o desenvolvimento de regiões que têm potencial de valorização imobiliária em detrimento de outras que continuam a passar na margem dos projetos do futuro e que receberão um contigente populacional que foi "expulso" da localidade que passou pelo processo de enobrecimento promovido pelo capital privado avalizado pelo Poder Público.

Entendemos que nestas situações o Estado deve tomar posturas ativas na efetivação de uma verdadeira justiça social. Essas posturas consubstanciam-se na utilização da tributação como instrumento de redução das desigualdades sócio-espaciais decorrentes da gentrificação. E nesse caso já contamos com contribuição de melhoria, espécie tributária com potencial de realizar justiça fiscal sem esquecer do princípio da capacidade contributiva.

\footnotetext{
${ }^{16}$ MACHADO, Hugo de Brito. Contribuição de Melhoria. Revista Fórum de Direito Tributário - RFDT. Belo Horizonte, ano 9, n. 50, p. 7-25, mar./abr. 2011. p. 24.
} 


\section{REFERÊNCIAS}

ABASCAL, Eunice H.; KATO, Volia; CYMROT, Raquel. Transformações da área-alvo da Operação Urbana Vila Leopoldina-Jaguaré pelo mercado imobiliário: a verticalização residencial como motor de desenvolvimento urbano. EURE (Santiago), v. 39, n. 116, p. 7599, 2013.

ALFONSIN, Betânia. "Operações Urbanas consorciadas como instrumento de captação de mais-valias urbanas: um imperativo da nova ordem jurídico-urbanística brasileira". In: FERNANDES, Edésio; ALFONSIN, Betânia (orgs). Direito Urbanístico no Brasil e no mundo. Belo Horizonte: Del Rey, 2004.

ÁVILA, Humberto. Teoria da Igualdade Tributária. São Paulo: Malheiros, 2008.

BALEEIRO, Aliomar. Uma Introdução à Ciência das Finanças. 18. ed. Atualizada por Hugo de Brito Machado Segundo. Rio de Janeiro: Forense, 2012.

BARRETTO, Margarita. Revitalização Urbana, Lazer e Turismo.Rosa Dos Ventos Turismo e Hospitalidade, v. 5, n. 4, 2013.

BATALLER, Maria Alba Sargatal. O estudo da gentrificação. Revista Continentes, v. 1, n.1, p. 9-37, 2013.

BRASIL. Ministério das Cidades. Secretaria de Programas Urbanos. Reabilitação de Centros Urbanos. Brasília: Ministério das Cidades, 2005.

CAMPOS, Helcio Ribeiro. Gentrificação na Área Central de Tiradentes/MG. In Revista Mercator, Fortaleza, v. 12, n. 29, p. 69-87, set./dez. 2013.

CARVALHO, Paulo de Barros. Curso de Direito Tributário. 25. ed. São Paulo: Saraiva, 2013.

CRESTANI, Andrei Mikhail Zaiatz. As faces (in) visíveis da regeneração urbana: rua Riachuelo e a produção de um cenário gentrificado. Cadernos Metrópole., v. 17, n. 33, p. 179$200,2015$.

FURTADO, Carlos Ribeiro. Intervenção do Estado e (re) estruturação urbana. Um estudo sobre gentrificação. Cadernos Metrópole., v. 16, n. 32, p. 341-363, 2014.

MACHADO, Hugo de Brito. Contribuição de melhoria. Revista Fórum de Direito Tributário - RFDT. Belo Horizonte, ano 9, n. 50, p. 7-25, mar./abr. 2011.

MACHADO, Hugo de Brito. Curso de Direito Tributário. 36. ed. São Paulo: Malheiros, 2015 . 
OLIVEIRA, Ana Carolina Rodrigues de. Agentes e Efeitos da Especulação Imobiliária em Ponta Grossa-PR. Raega-O Espaço Geográfico em Análise, v. 28, p. 106-133, 2013.

PAUPÉRIO, Fernanda Pismel. Gentrificação e Patrimônio: O passado revisto pelas Instituições Culturais em um Antigo Bairro Industrial Em Lyon, França. 103f. 2012. Dissertação (Mestrado em Sociologia). Universidade Federal do Paraná - Curitiba, 2012.

PEREIRA, Alvaro Luiz dos Santos. Intervenções em centros urbanos e conflitos distributivos: modelos regulatórios, circuitos de valorização e estratégias discursivas. 308f. 2015. Tese (Doutorado em Direito). Universidade de São Paulo - São Paulo, 2015.

PIKETTY, Thomas. O capital no século XXI. Tradução de Monica Baumgarten de Bolle. Rio de Janeiro: Intrínsseca, 2014.

RIBEIRO, Ricardo Lodi. Piketty e a Reforma Tributária igualitária no Brasil. Revista de Finanças Públicas, Tributação e Desenvolvimento - RFPTD, v.3, n.3. Rio de Janeiro: UERJ, 2015. Disponível em: www.e-publicacoes.uerj.br/index.php/rfptd/article/view/15587

RIBEIRO, Ricardo Lodi. O capital no século XXI e a justiça fiscal: uma contribuição de Thomas Piketty para uma reforma tributária no Brasil. Revista de Direito Público de Economia - RDPE. Ano 13, n. 50, p. 197-28. abr./jun. 2015.

SANTOS, André da Rocha. Revitalização para quem? Política urbana e gentrificação no Centro de Santos. Cadernos Metrópole, v. 16, n. 32, p. 587-607, 2014.

SMITH, Neil. A gentrificação generalizada: de uma anomalia local à "regeneração" urbana como estratégia urbana global. In: BIDOU-ZACHARIASEN, Catherine (Org). De volta à cidade. São Paulo: ANNABLUME, 2006. p. 59-87.

WACQUANT, Loïc. RESSITUANDO A GENTRIFICAÇÃO: a classe popular, a ciência e o Estado na pesquisa urbana recente. Caderno CRH, v. 23, n. 58, 2010.

ZOLINI, Gustavo Pimenta de Pádua. A Inflexão do Conceito Gentrificação em Conjuntos Urbanos Patrimoniais Em Cidades De Pequeno Porte: Os Casos Mineiros De São Thomé Das Letras E Tiradentes. 181f. 2007. Dissertação (Mestrado em Arquitetura). Universidade Federal de Minas Gerais - Belo Horizonte, 2007. 